\title{
A patient-preference cohort study of office versus inpatient uterine polyp treatment for abnormal uterine bleeding
}

\author{
Natalie A. M. Cooper ${ }^{1} \cdot$ Lee Middleton ${ }^{2} \cdot$ Paul Smith $^{3,4}$ • Elaine Denny ${ }^{5}$. \\ Lynda Stobert $^{6}$ - Jane Daniels ${ }^{2}$ - T. Justin Clark ${ }^{3,7}$ on behalf of the OPT trial \\ collaborative group
}

Received: 10 April 2015 / Accepted: 5 April 2016/Published online: 17 May 2016

(C) The Author(s) 2016. This article is published with open access at Springerlink.com

\begin{abstract}
Uterine polyps can cause abnormal bleeding in women. Conventional practise is to remove them under general anaesthesia but advances in technology have made it possible to perform polypectomy in the office setting. We conducted a patient-preference study to explore women's preferences for treatment setting and to evaluate the effectiveness and treatment experience of women undergoing uterine polypectomy. Three hundred ninety-nine women with abnormal uterine bleeding who were found to have uterine polyps at diagnostic hysteroscopy were recruited. Office polypectomies were performed in office hysteroscopy clinics, and inpatient procedures were undertaken in operating theatres. Three hundred twenty-four of $399(81 \%)$ expressed a preference for office treatment. There was no difference found between office treatment and inpatient
\end{abstract}

T. Justin Clark

justin.clark@bwhct.nhs.uk

1 Women's Health Research Unit, Queen Mary University of London, London E1 2AT, UK

2 Birmingham Clinical Trials Unit, University of Birmingham, Birmingham B15 2TT, UK

3 Birmingham Women's NHS Foundation Trust, Birmingham B15 2TG, UK

4 School of Clinical and Experimental Medicine, University of Birmingham, Birmingham B15 2TT, UK

5 Centre for Health and Social Care Research, Birmingham City University, Birmingham B15 3TN, UK

6 School of Allied and Public Health Professions, Birmingham City University, Birmingham B15 3TN, UK

7 OPT Trial Office, Birmingham Clinical Trials Unit, College of Medical and Dental Sciences, Robert Aitken Institute for Clinical Research, University of Birmingham, Edgbaston, Birmingham B15 2TT, UK treatment in terms of alleviating abnormal uterine bleeding as assessed by patients and in improving disease-specific quality of life. Acceptability was lower and patient pain scores were significantly higher in the office group. When offered a choice of treatment setting for uterine polypectomy, patients have a preference for office over inpatient treatment. Ambulatory gynaecology services should be available within healthcare systems to meet patient demand.

Keywords Office polypectomy · Abnormal uterine bleeding • Patient preference $\cdot$ Ambulatory gynaecology $\cdot$ Uterine polyp

\section{Introduction}

Abnormal uterine bleeding affects women of all ages and is the commonest reason for referral to secondary care [1,2]. Uterine polyps are commonly found in association with abnormal uterine bleeding in both pre- and postmenopausal women [3-7] when investigated with ultrasound or office hysteroscopy. Whilst the risk of occult malignancy within uterine polyps is low, the available evidence supports the current practise of surgically removing uterine polyps to help alleviate bleeding symptoms $[8,9]$ and this has traditionally been performed under general anaesthesia. However, with advances in endoscopic technology, it is now possible to perform uterine polypectomy under hysteroscopic guidance in an office setting without the need for hospital admission and anaesthesia [10-12]. Furthermore, treatment can be carried out at the same time as diagnosis; the "see \& treat" approach [13].

Whilst recruiting to a randomised controlled non-inferiority study which compared office to inpatient polypectomy, we collected data from women who consented to be followed-up, but had a preference for how they were treated and so could not be randomised. We designed this parallel observational study 
because a pilot RCT to aid the final office polyp treatment (OPT) study design (www.birmingham.ac.uk/research/ activity/mds/trials/bctu/trials/womens/opt/index.aspx) had suggested that a substantial proportion of women would exert a preference for treatment setting. We therefore wanted to explore women's preferences for treatment setting and to evaluate the effectiveness and treatment experience of women when undergoing uterine polypectomy for alleviating abnormal bleeding according to their preference.

\section{Methods}

\section{Population}

All women with abnormal uterine bleeding and a uterine polyp diagnosed at office hysteroscopy [13] were eligible to be recruited into the office polyp treatment (OPT) study. Women in equipoise were recruited to the randomised study [14] and those with a preference for treatment were asked to participate in the preference study as we describe here. Abnormal uterine bleeding included heavy menstrual bleeding, intermenstrual bleeding and postmenopausal bleeding. Women were excluded if office polypectomy was considered not feasible, malignancy was suspected or another surgical uterine intervention was needed. All participants provided written informed consent. In clinics which provided a 'see and treat' service, consent was obtained and the patient was registered on the on-line recruitment system prior to the diagnostic hysteroscopy, so that if a uterine polyp was diagnosed and the woman's preference was for office polypectomy, treatment could be performed straight away without an interruption to register the patient into the study.

\section{Procedures}

Following the diagnostic hysteroscopy, women who agreed to participate in the preference study had their choice of treatment arranged. Those who chose office polypectomy underwent the procedure immediately following diagnosis in most instances, although some participants had their treatment scheduled within the following 8 weeks. Office polypectomies were performed in the office hysteroscopy clinic and inpatient procedures were performed in operating theatres, under general or regional anaesthesia. Office polyp removal was carried out under direct hysteroscopic vision using miniature mechanical (scissors, biopsy cups and grasping forceps) or electrosurgical instruments (bipolar electrodes), with or without the need for minor degrees of cervical dilatation and local anaesthesia (direct cervical infiltration or paracervical injection). Blind avulsion with small polypectomy forceps was also allowed. Women who chose inpatient polypectomy could have traditional dilatation and curettage or removal under vision using a resectoscope. Clinicians were free to choose the operative technique for polypectomy. Endometrial biopsy and medical therapies were permitted when indicated.

\section{Outcome measures and follow-up}

Our main measure of interest was successful treatment, determined by the women's assessment of their bleeding at 6 months using a dichotomous (success/fail) outcome measure. For women with heavy menstrual bleeding, treatment was considered a success if bleeding had reduced to acceptable levels. For women with intermenstrual or postmenopausal bleeding, the definition was cessation of bleeding.

Other patient reported outcome measures were the women's subjective assessment of their bleeding using visual-analoguescales ( 0 for no bleeding to 100 heaviest imaginable and 0 for no days bleeding to 100 bleeding every day) and response to the question 'compared to before your treatment, would you say your bleeding is?' on an ordered Likert scale (much better, little better, same, worse). Health-related-quality-of-life was measured using the generic EuroQol EQ-5D-3L [15] and the disease-specific Menorrhagia Multi-Attribute Scale (MMAS) [16]. All clinical data were collected at baseline and then by mail at 6 months post recruitment.

Patient experience was also evaluated; patients were asked to rate their level of pain $1 \mathrm{~h}$ after the procedure and on discharge from hospital using visual-analogue-scales ( 0 no pain to 100 worst imaginable pain). Women undergoing office polypectomy also rated the level of pain during the procedure. Acceptability of the procedure was assessed using Likert scales and structured questions. This was supplemented by a series of semi-structured qualitative telephone interviews in a purposive sample of women (who had consented to be interviewed) 1 week after the procedure. Rates of successful polyp removal and complications were recorded peri-operatively, and postoperative data were collected for adverse events and need further treatment.

\section{Statistical analysis}

Analyses were performed including all consenting participants in the group of their preference regardless of whether they received their preference, or indeed any, treatment (i.e. intention-to-treat). Chi-squared and $t$ tests were used to assess if there were any systematic differences between the preference groups in terms of their baseline characteristics. Odds ratios for successful treatment at 6 month were generated using a logistic regression model (odds ratios were favoured over risk ratios as it is more straightforward to generate stable adjusted estimates [17]. Estimates were adjusted for potential confounders that were considered to be the most clinically important by adding the following 12 variables to the model: predominant bleeding complaint at consent (post- 
menopausal/heavy menstrual/intermenstrual), site of uterine polyp (fundal/non-fundal), type of uterine polyp (glandular/ fibrous), number of polyps $(1 / 2 / 3+)$, largest polyp size (continuous variable), grade of surgeon (consultant/less experienced), removal technique (blind/hysteroscopic), detachment technique (electrode/mechanical), age (continuous variable), body mass index (continuous variable), parity $(0 / 1 / 2 / 3 / 4+)$, and centre of recruitment (Birmingham Women's Hospital/ Royal Hallamshire Hospital Sheffield/other minor centre). A multiple imputation procedure [18] (assumed data was missing at random) was used in this analysis to impute any missing data items. Variables in the imputation model included the outcome variable of interest together with the parameters listed above; 20 imputed data sets were created using the MCMC method with overall estimates and standard error calculated using Rubin's rules [19]. $95 \%$ confidence intervals were generated along with a $p$ value from the associated twosided chi-squared test. Other binary outcomes and endpoints measured on a continuous scale (scores from MMAS, EQ-5D and VAS scores) were analysed in a similar fashion to the above (linear regression model adjusting for baseline score for continuous variables). Unadjusted estimates are provided for comparison or where an adjustment was not possible because of low group frequencies. No adjustments were made for operative descriptors. Standard tests were used for other outcome measures: paired $t$ tests for changes from baseline scores within groups and two-sample $t$ tests for continuous data with a normal distribution, Wilcoxon signed rank test for skewed continuous data and chi-squared tests for binary and categorical responses. SAS version 9.2 was used for analyses (PROC MI for the multiple imputation procedure).

\section{Results}

\section{Recruitment and qualitative assessment of patients' preference for treatment}

Between April 2008 and July 2011, in 30 UK NHS centres, 952 women with abnormal uterine bleeding and a preference for how they wanted to be treated agreed to participate. Three hundred ninety-nine $(42 \%)$ women were recruited with the main reason for ineligibility being no polyp present at diagnostic hysteroscopy. Three hundred twenty-four of 399 (81\%) expressed a preference for office treatment (Fig. 1).

Thirteen women underwent qualitative interviews. Women were asked about their treatment preferences, which were mainly down to individual reasons. Most women choosing office treatment wanted it over and done within one hospital visit, and even though for one of these women the procedure could not be completed she still thought it was the right choice. Of the other women, two had a fear of anaesthetics, one had a pre-existing medical condition, one had children to make arrangements for and one did not want to take time off work. Very few women in the overall preference study chose inpatient treatment and the four interviewed all spoke of a previous bad experience of hysteroscopy or other procedures under local anaesthetic, or embarrassment at being in stirrups, which made them want a general anaesthetic. In both groups of the study, a number of women told of how they had consulted friends and family before attending the clinic, or the nurse in the clinic, in order to make a decision about the procedure, but this had to be weighed up against their personal feelings.

\section{Participants and follow-up}

There were no statistically significant differences between groups in the baseline characteristics of the women (Table 1). Overall, for $48 \%$ (192/399) of the women, the initial complaint was postmenopausal bleeding; $25 \%$ (98/ 399) had heavy menstrual bleeding and the remaining participants had intermenstrual bleeding, 109/399 (27\%). Three hundred two of 324 (93\%) of the office group received their treatment preference compared with 68/75 (91\%) of the inpatient group (Fig. 1). Sixty-three percent of the women allocated to office polypectomy were treated in 'see and treat' clinics. The median time from recruitment to treatment in the office groups and inpatient group were 0 days $(\mathrm{IQR}=0$, 27 ) and 31 days $(\mathrm{IQR}=7,55)$, respectively. Completed primary outcome responses were available from 338/399 (85\%) of participants at 6 months (Fig. 1).

\section{Treatment success}

There was no significant difference between treatment success in the office and inpatient polypectomy groups with $82 \%$ in each group reporting successful alleviation of bleeding symptoms at 6 months $(231 / 283$ versus $45 / 55$, unadjusted $\mathrm{OR}=0.99,95 \% \mathrm{CI}=0.47,2.09 ; p>0.9 ;$ adjusted $\mathrm{OR}=1.12,95 \% \mathrm{CI}=0.47,2.69 ; p=0.8$ ).

\section{Operative results}

Table 2 details the operative and postoperative results details. Office treatment required less vaginal instrumentation $(\mathrm{OR}=0.13,95 \% \mathrm{CI}=0.06,0.31 ; p<0.001)$ and dilatation of the cervix $(\mathrm{OR}=0.15,95 \% \mathrm{CI}=0.08,0.28 ; p<0.001)$. Hysteroscopic polypectomy under direct vision was significantly more common $(\mathrm{OR}=3.6,95 \% \mathrm{CI}=2.0,6.4$; $p<0.001)$ in the office setting, with electrosurgery being the most popular method of detaching polyps $(\mathrm{OR}=2.0,95 \%$ $\mathrm{CI}=1.2,3.5 ; p=0.02)$. Hysteroscopic retrieval of specimens from the uterine cavity was the most common technique in the office setting whereas blind mechanical extraction was preferred in the inpatient group $(\mathrm{OR}=5.6,95 \% \mathrm{CI}=3.0,10.4$; $p<0.001)$. The proportion of complete removals was not 
Fig. 1 Flow diagram showing enrollment, preference for treatment and follow-up of the study patients

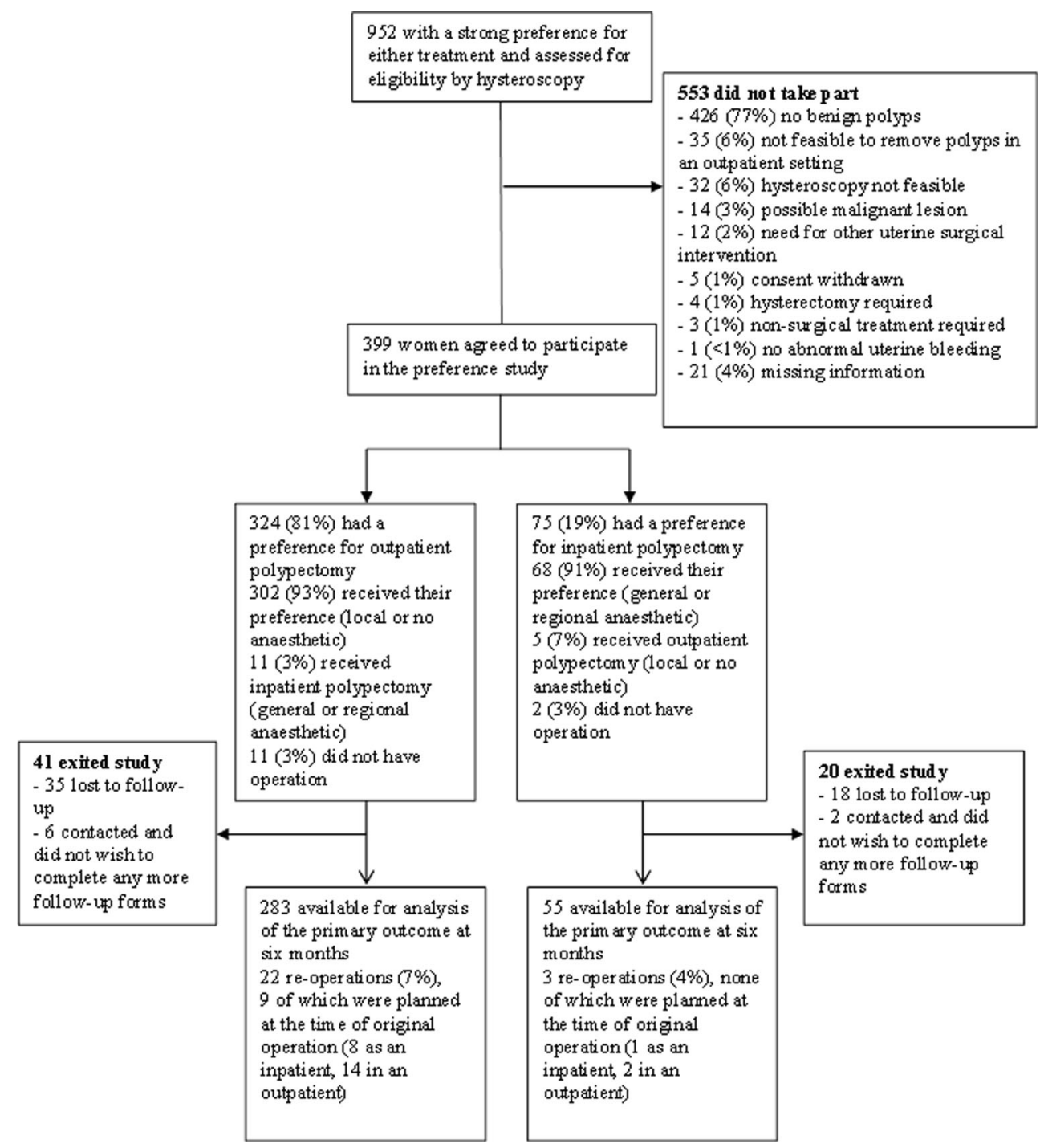

significantly different between groups (282/312 [90\%] versus 68/73 [93\%], unadjusted $\mathrm{OR}=1.4,95 \% \mathrm{CI}=0.5,3.9$; $p=0.5$; adjusted $\mathrm{OR}=1.9,95 \% \mathrm{CI}=0.7,5.6 ; p=0.2$ ).

\section{Serious adverse events}

No serious adverse events occurred in the preference study. The most common perioperative complications in the office group were induced vaso-vagal reactions affecting $6 \%$ of the cohort. Vaso-vagal reactions also occurred postoperatively with a similar percentage in each cohort (5\% of the office group versus $3 \%$ of the inpatient group) (Table 2).

\section{Quality of life and bleeding scores}

Condition-specific quality of life and bleeding scores were significantly improved from baseline at 6 months in both groups with no significant differences between them (Table 3 ). Generic quality of life scores (Euroqol EQ-5D) were improved from baseline in the office group but not in the inpatient group with no difference between the groups at 6 months. The nonsignificant increase within the inpatient group may be due to the relatively small number of women in this group.

\section{Procedure acceptability}

Mean pain scores were significantly higher in the office polypectomy group compared with the inpatient group at 1-h post procedure and on discharge (Table 3). Two percent (7/299) of women in the office group compared with no women in the inpatient group felt that the procedure they underwent was 'unacceptable'. There was no difference between groups in terms of the number of women who would recommend the procedure to a friend, choose to have the same procedure again or in retrospect would have preferred the alternative treatment. In qualitative interviews, the preference 
Table 1 Baseline characteristics of the patients

\begin{tabular}{|c|c|c|c|c|}
\hline & & $\begin{array}{l}\text { Office } \\
\text { polypectomy } \\
(n=324)\end{array}$ & $\begin{array}{l}\text { Inpatient } \\
\text { polypectomy } \\
(n=75)\end{array}$ & $p$ value \\
\hline Age (years) & Mean (SD) & $53(11)$ & $51(12)$ & $p=0.2$ \\
\hline BMI $\left(\mathrm{kg} / \mathrm{m}^{2}\right)$ & Mean (SD) & $31(8)^{\mathrm{a}}$ & $31(8)^{\mathrm{b}}$ & $p=0.7$ \\
\hline \multirow[t]{4}{*}{ Ethnicity } & $\begin{array}{l}\text { White } \\
\text { Asian }\end{array}$ & $\begin{array}{l}263(91 \%) \\
12(4 \%)\end{array}$ & $\begin{array}{l}54(93 \%) \\
2(3 \%)\end{array}$ & \multirow[t]{4}{*}{$p>0.9$} \\
\hline & Black & $8(3 \%)$ & $1(2 \%)$ & \\
\hline & Other & $6(2 \%)$ & $1(2 \%)$ & \\
\hline & Not given/not known & 35 & 17 & \\
\hline \multirow[t]{2}{*}{ Recruiting centre } & $\begin{array}{l}\mathrm{BWH}^{\mathrm{c}} \\
\mathrm{RHH}^{\mathrm{d}}\end{array}$ & $\begin{array}{l}105(32 \%) \\
60(19 \%)\end{array}$ & $\begin{array}{l}24(32 \%) \\
18(24 \%)\end{array}$ & \multirow[t]{2}{*}{$p=0.5$} \\
\hline & Others $^{\mathrm{e}}$ & $159(49 \%)$ & $33(44 \%)$ & \\
\hline \multirow{2}{*}{$\begin{array}{l}\text { Predominant } \\
\text { bleeding } \\
\text { complaint at } \\
\text { randomisation }\end{array}$} & $\begin{array}{l}\text { Post-menopausal }^{\mathrm{f}} \\
\text { Heavy menstrual }^{\mathrm{g}}\end{array}$ & $\begin{array}{l}155(48 \%) \\
75(23 \%)\end{array}$ & $\begin{array}{l}37(49 \%) \\
23(31 \%)\end{array}$ & \multirow[t]{2}{*}{$p=0.2$} \\
\hline & Intermenstrual $^{\mathrm{h}}$ & $94(29 \%)$ & $15(20 \%)$ & \\
\hline Site of uterine polyp & $\begin{array}{l}\text { Fundal } \\
\text { Non-fundal }\end{array}$ & $\begin{array}{l}118(36 \%) \\
206(64 \%)\end{array}$ & $\begin{array}{l}25(33 \%) \\
50(67 \%)\end{array}$ & $p=0.6$ \\
\hline Type of uterine polyp & $\begin{array}{l}\text { Glandular } \\
\text { Fibrous }\end{array}$ & $\begin{array}{l}229(71 \%) \\
95(29 \%)\end{array}$ & $\begin{array}{l}53(71 \%) \\
22(29 \%)\end{array}$ & $p>0.9$ \\
\hline \multirow[t]{2}{*}{ Number of polyps } & $\begin{array}{l}1 \\
2\end{array}$ & $\begin{array}{l}233(72 \%) \\
62(19 \%)\end{array}$ & $\begin{array}{l}58(77 \%) \\
11(15 \%)\end{array}$ & \multirow[t]{2}{*}{$p=0.6$} \\
\hline & $>=3$ & $29(9 \%)$ & $6(8 \%)$ & \\
\hline \multirow[t]{5}{*}{ Parity } & $\begin{array}{l}0 \\
1\end{array}$ & $\begin{array}{l}49(15 \%) \\
35(11 \%)\end{array}$ & $\begin{array}{l}18(24 \%) \\
6(8 \%)\end{array}$ & \multirow[t]{5}{*}{$p=0.4$} \\
\hline & 2 & $121(37 \%)$ & $26(35 \%)$ & \\
\hline & 3 & $50(15 \%)$ & $9(12 \%)$ & \\
\hline & $>=4$ & $37(11 \%)$ & $8(11 \%)$ & \\
\hline & missing & $32(10 \%)$ & $8(11 \%)$ & \\
\hline \multirow{5}{*}{$\begin{array}{c}\text { Other benign } \\
\text { pathology }\end{array}$} & None & $318(98 \%)$ & $74(99 \%)$ & \multirow[t]{5}{*}{$p=0.8$} \\
\hline & $\begin{array}{l}\text { SMF/Adhesion/ } \\
\text { Septum }\end{array}$ & - & - & \\
\hline & Adhesion/Septum & - & - & \\
\hline & SMF & $5(2 \%)$ & $1(1 \%)$ & \\
\hline & Septum & $1(<1 \%)$ & - & \\
\hline
\end{tabular}

SMF submucosal fibroid

${ }^{\mathrm{a}}$ Based on 56 values

${ }^{\mathrm{b}}$ Based on 207 values

${ }^{\mathrm{c}}$ Birmingham Women's Hospital

${ }^{\mathrm{d}}$ Royal Hallamshire Hospital, Sheffield

${ }^{\text {e }} 28$ other centres: median recruitment $=4(\operatorname{IQR}=[2,9])$

${ }^{\mathrm{f}} 16(10 \%)$ and $3(8 \%)$ of these women were currently taking a continuous combined 'no bleed' HRT in the office and inpatient groups, respectively

${ }^{\mathrm{g}}$ Includes one post-menopausal woman (1\%) on a sequential HRT (office group)

${ }^{\mathrm{h}}$ Includes two post-menopausal women ( $2 \%$ ) on a sequential HRT (office group) patients reported less pain than the randomised ones, using descriptions such as 'uncomfortable', 'bearable' and 'better than expected'. This group also reported little postoperative pain describing it like 'wind' or 'period pain'. They balanced pain, which they mainly experienced short term, with the convenience of a fast response to their problem.

\section{Additional treatments}

There was no difference between groups in the number of women using additional medical treatments for their bleeding, or consulting a healthcare provider during the 6-month follow-up period. Twenty-two women in the office group (7\%) 
Table 2 Operative details and complications

\begin{tabular}{|c|c|c|c|}
\hline & Office polypectomy & Inpatient polypectomy & Mean difference or OR $(95 \% \mathrm{CI})^{\mathrm{b}}, p$ value \\
\hline $\begin{array}{l}\text { Largest polyp size, } \mathrm{cm} \\
(\text { median }[\mathrm{IQR}], \mathrm{n})^{\mathrm{a}}\end{array}$ & $1.1[0.8-2.0], 286$ & $1.0[0.8-2.0], 57$ & $0.0(-0.2,0.2), p>0.9$ \\
\hline Need for cervical dilation $=$ yes & $105 / 303(35 \%)$ & $52 / 67(78 \%)$ & $0.15(0.08,0.28), p<0.001$ \\
\hline Use of vaginal speculum = yes & $152 / 301(50 \%)$ & $53 / 60(88 \%)$ & $0.13(0.06,0.31), p<0.001$ \\
\hline Use of local anaesthetic $=$ yes & $132 / 313(42 \%)$ & $2 / 73(3 \%)$ & $25.9(6.2,107), p<0.001$ \\
\hline $\begin{array}{l}\text { Hysteroscopic removal = yes } \\
\text { (vs. blind) }\end{array}$ & $246 / 299(82 \%)$ & $36 / 64(56 \%)$ & $3.6(2.0,6.4), p<0.001$ \\
\hline Scope diameter $(\mathrm{mm})$ & $4.0[4.0-6.0], 201$ & $5.5[4.0-6.0], 42$ & $-1.0(-1.0,-1.0), p<0.001$ \\
\hline Method used to detach & $n=287$ & $n=65$ & $2.0(1.2,3.5)^{\mathrm{c}}, p=0.02$ \\
\hline Electrode & $155(54 \%)$ & $24(37 \%)$ & \\
\hline Mechanical & $102(36 \%)$ & $35(54 \%)$ & \\
\hline Combination & $30(10 \%)$ & $6(9 \%)$ & \\
\hline Method of retrieval & $n=292$ & $n=62$ & $5.6(3.0,10.4)^{\mathrm{d}}, p<0.001$ \\
\hline Hysteroscopic & $193(66 \%)$ & $16(26 \%)$ & \\
\hline Mechanical & $69(24 \%)$ & $43(69 \%)$ & \\
\hline Combination & $11(4 \%)$ & - & \\
\hline None & $19(7 \%)$ & $3(5 \%)$ & \\
\hline Surgeon grade $=$ consultant & $233 / 305(76 \%)$ & $40 / 67(60 \%)$ & $2.2(1.3,3.8), p=0.005$ \\
\hline $\begin{array}{l}\text { Time taken for polypectomy, min } \\
\text { (median [IQR], n) }\end{array}$ & $10[5-15], 290$ & $10[7-15], 52$ & $-1.5(3.0,0.0), p=0.3$ \\
\hline $\begin{array}{l}\text { Time in office room/theatre, min } \\
\text { (median [IQR], n) }\end{array}$ & $30[20-35], 285$ & 33 [25-45], 53 & $-6.0(-10.0,-2.0), p=0.003$ \\
\hline Removal success & $n=312$ & $n=73$ & $1.4(0.5,3.9)^{\mathrm{f}}, p=0.5$ \\
\hline Complete & $282(90 \%)$ & $68(93 \%)$ & \\
\hline Partial $^{\mathrm{e}}$ & $22(7 \%)$ & $3(4 \%)$ & \\
\hline Failed $^{\mathrm{e}}$ & $8(3 \%)$ & $2(3 \%)$ & \\
\hline Operative complications & $n=302$ & $n=67$ & \\
\hline Vaso-vagal episode & $17(6 \%)$ & - & \\
\hline Patient discomfort & $9(3 \%)$ & - & \\
\hline Cervical trauma & $1(<1 \%)$ & $1(1 \%)$ & \\
\hline Uterine perforation & - & - & \\
\hline Other $^{g}$ & $1(<1 \%)$ & - & \\
\hline Postoperative complications & $n=301$ & $n=67$ & \\
\hline Vaso-vagal episode & $14(5 \%)$ & $2(3 \%)$ & \\
\hline Vomiting & $3(1 \%)$ & $2(3 \%)$ & \\
\hline Severe pain & - & $2(3 \%)$ & \\
\hline Further treatment/procedure given & $n=292$ & $n=64$ & \\
\hline Mirena IUS & $42(14 \%)$ & $8(13 \%)$ & \\
\hline Tranexamic acid & $9(3 \%)$ & - & \\
\hline Progestogens & $3(1 \%)$ & - & \\
\hline Endometrial destruction & $2(1 \%)$ & - & \\
\hline Local oestrogen cream & $2(1 \%)$ & - & \\
\hline Mefenamic acid & $1(<1 \%)$ & $1(2 \%)$ & \\
\hline Contraceptive pill & $1(<1 \%)$ & - & \\
\hline Missing treatment name & $2(1 \%)$ & $1(2 \%)$ & \\
\hline
\end{tabular}

Numbers in italics refer to the responses received for that particular question

$\mathrm{n}=$ number of responses

${ }^{a}$ Polyp size was estimated hysteroscopically

${ }^{\mathrm{b}}$ Mean difference $<0$ indicates lower with office, similarly $\mathrm{OR}<1$ is lower with office. For skewed variables presented with medians, differences in location between groups were calculated using Hodges-Lehmann estimates and Moses' confidence intervals

c Odds ratio calculated from 'electrode' versus any other category

d Odds ratio calculated from 'hysteroscopic' versus any other category

${ }^{\mathrm{e}}$ Nine (3\%) partial or failed patients in the office group and none in the inpatient group were immediately scheduled for reoperation. Six of these were scheduled to be an inpatient. Partial or failed reasons in the office group (\%'s given of the total number, 312): patient discomfort (9, $3 \%$ ), unable to locate blindly $(5,2 \%)$, unable to access under vision $(4,1 \%)$, polyp too large $(3,1 \%)$, failed hysteroscopy $(1,<1 \%)$, base cut but unable to remove $(1$, $<1 \%)$, wide base unable to fully resect $(1,<1 \%)$, vaso-vagal episode $(1,<1 \%)$, difficult access to base of polyp $(1,<1 \%)$, missing reason $(4,1 \%)$; partial or failed reasons in the inpatient group (\%'s given of the total number, 73$)$ : unable to access under vision (1, $1 \%)$, unable to locate blindly (1, $1 \%)$, deep sub-mucous fibroid polyp $(1,1 \%)$, too broad base $(1,1 \%)$, missing reason $(1,1 \%)$

${ }^{\mathrm{f}}$ Odds ratio calculated from 'partial' or 'failed' versus complete

${ }^{\mathrm{g}}$ Other complications: nausea 
Table 3 Results of quality of life assessments, bleeding and pain scores and procedure acceptability

Office polypectomy Inpatient polypectomy

Mean $(\mathrm{SD}, n) \quad$ Mean $(\mathrm{SD}, n) \quad$ Difference $(95 \% \mathrm{CI})^{\mathrm{a}}, p$ value $\quad$ Adjusted difference ${ }^{\mathrm{h}}(95 \% \mathrm{CI}), p$ value

$\mathrm{MMAS}^{\mathrm{b}}$

Baseline $\quad 63(26,163) \quad 61(28,37)$

6 months

$77(25,135)^{\mathrm{g}}$

$79(25,25)^{\mathrm{g}}$

$-3(-12,7), p=0.55$

$-4(-14,3), p=0.18$

EuroQol EQ-5D

Baseline

$0.79(0.26,312) \quad 0.72(0.30,71)$

6 months

$0.82(0.25,289)^{\mathrm{g}} \quad 0.81(0.30,56)$

EuroQol health thermometer ${ }^{\mathrm{d}}$

Baseline $78(18,305) \quad 75(21,71)$

6 months $\quad 78(19,291) \quad 79(20,57)$

Bleeding duration visual analogue scale ${ }^{\mathrm{e}}$
Baseline
$39(26,74)$

$$
38(26,23)
$$

$0.00(-0.07,0.06), p=0.88$

$0.01(-0.05,0.08), p=0.64$

$-2(-7,3), p=0.34$

$-1(-4,5), p=0.81$

6 months

$30(28,65)^{\mathrm{g}}$

Bleeding amount visual analogue scale $\mathrm{f}^{\mathrm{f}}$

Baseline $\quad 59(28,75)$

6 months $\quad 32(28,68)^{\mathrm{g}}$

$18(19,16)^{\mathrm{g}}$

Operation pain scores

During procedure ${ }^{\mathrm{i}}$ 60 min after procedure ${ }^{i}$

On discharge ${ }^{\mathrm{i}}$

$42(26,296)$

$27(24,247)$

$22(21,276)$

$n(\%)$

$58(26,23)$

$26(27,16)^{\mathrm{g}}$

Operation acceptability

Totally

Generally

$194(65 \%)$

$48(16 \%)$

Fairly

Unacceptable

$50(17 \%)$

$7(2 \%)$

Exposure embarrassing?

$\begin{array}{lll}\text { Extremely } & 5(2 \%) & 2(3 \%) \\ \text { Moderately } & 30(10 \%) & 7(12 \%) \\ \text { A little } & 90(30 \%) & 8(13 \%) \\ \text { No } & 177(59 \%) & 43(72 \%)\end{array}$

Recommend to a friend?

Yes/total

$$
\text { 282/302 (93\%) }
$$

62/64 (97\%)

$-13(-27,2), p=0.09$

$-13(-27,2), p=0.09$

$20(24,60)$

$13(18,57)$

$n(\%)$

$-4(-19,11), p=0.61$

$-3(-20,14), p=0.72$

$52(81 \%)$

$9(14 \%)$

$3(5 \%)$

$0(-)$

Same treatment again?

Yes/total

283/300 (94\%)

Preferred alternative treatment?

Yes/total

$36 / 299(12 \%)$

$62 / 63(98 \%)$

$-7(-14,0), p=0.04$

$-9(-15,-3), p=0.003$

OR (95\% CI), $p$ value

$-8(-11,-4), p=0.03$

$-9(-15,-3), p=0.002$

Adjusted $\mathrm{OR}^{\mathrm{h}}(95 \% \mathrm{CI}), p$ value

$0.21(0.06,0.69), p=0.01^{\mathrm{k}}$

$0.19(0.05,0.70), p=0.01^{\mathrm{k}}$

$1.4(0.6,3.0), p=0.46^{1}$

$1.4(0.6,3.7), p=0.36^{1}$

$10 / 63(16 \%)$
$0.45(0.10,2.0), p=0.28$

$0.27(0.04,2.1), p=0.21$

$1.4(0.7,3.0), p=0.41$
Not possible to compute

Not possible to compute

$1.5(0.7,3.5), p=0.32$

$n$ number of responses

${ }^{\text {a }}$ Difference between groups at each time point adjusted for baseline score. Estimates of differences $>0$ favour office polypectomy, those $<0$ favour inpatient polypectomy

${ }^{\mathrm{b}}$ Menorrhagia Multi-Attribute Scale questionnaire. Scores range from 0 (severely affected) to 100 (not affected). Restricted to those with heavy menstrual and intermenstrual bleeding only

${ }^{\mathrm{c}}$ Health-related quality of life questionnaire. Scores range from -0.59 (health state worse than death) to 1.0 (perfect health state)

${ }^{\mathrm{d}}$ Health-related quality of life questionnaire. Scores range 0 (worst imaginable health state) to 1.0 (best imaginable health state)

${ }^{\mathrm{e}}$ Visual Analogue Scale score. Scores range from 0 (no days of bleeding in the last month) to 100 (bleeding every day in the last month). Restricted to those with heavy menstrual bleeding only

${ }^{\mathrm{f}}$ Visual Analogue Scale score. Scores range from 0 (no bleeding in the last month) to 100 (heaviest imaginable bleeding in the last month). Restricted to those with heavy menstrual bleeding only

${ }^{\mathrm{g}} p<0.05$ when compared with baseline score within group (by paired $t$ test)

${ }^{\mathrm{h}}$ See statistical methods section for details on adjustments

iVisual Analogue Scale score. Scores range from 0 (no pain at all) to 100 (worst imaginable pain). $T$ test used for analysis

${ }^{\mathrm{j}}$ Estimates of OR $>1$ favour office polypectomy, those $<1$ favour inpatient polypectomy

${ }^{\mathrm{k}}$ Totally acceptable/generally acceptable vs. fairly acceptable/unacceptable combined categories used to calculate odds ratio

${ }^{1}$ Extremely/moderately vs. a little/no combined categories used to calculate odds ratio 
and three in the inpatient group ( $4 \%$ ) had at least one further polyp removal $(\mathrm{OR}=1.75,95 \% \mathrm{CI}=0.51,6.00 ; p=0.4)$. The total number of women undergoing subsequent gynaecological operations other than polyp removal was higher with office polypectomy (27 [8 \%] versus 3 [4 \%]) but this difference was not statistically significant $(\mathrm{OR}=1.86,95 \% \mathrm{CI}=0.55,6.35 ; p=0.3)$. These operations comprised the following in the office versus inpatient groups, respectively: hysteroscopy, $9(3 \%)$ versus $2(3 \%)$; hysterectomy, $9(3 \%)$ versus $1(2 \%)$ and endometrial ablation, $3(1 \%)$ versus 0 . The other six operations were in the office group: five cyst removals $(2 \%)$ and one ovary removal $(<1 \%)$.

\section{Discussion}

The results of this study demonstrate that women with abnormal uterine bleeding and uterine polyps, who have a preference for how they are treated, are more likely to choose office polypectomy than an inpatient procedure. At 6 months, we found no differences between office and inpatient treatment in terms of treating abnormal uterine bleeding and over $80 \%$ women reported successful alleviation of symptoms, regardless of initial bleeding complaint. The duration and amount of bleeding were significantly reduced following both office and inpatient treatment, and no differences were identified according to treatment preference. Similarly, a non-differential but significant improvement in disease-specific quality of life was seen following polypectomy, although generic quality of life appeared only marginally improved.

There was no increased risk of partial or failed polypectomy in the office group in the preference study which is contradictory to the results of the randomised OPT study [14] which found that office treatment was more likely to fail. This is likely to be due to unknown confounders and the small sample size in the inpatient group. Overall pain scores were still significantly higher in the office group than in the inpatient group but these differences were small and so their clinical significance is debatable; differences between groups in the amount of postoperative medication may also have affected this to an unknown degree. Only $2 \%$ of office patients felt that the procedure was unacceptable; findings that are consistent with the concomitant RCT. Not all women underwent their preferred treatment. We can hypothesise that women may have changed their mind about which treatment they wanted but we are unable to provide data as the reasons were not recorded.

In the qualitative interviews, women who had a preference for office treatment appeared to report less pain than those who were randomised to the office setting. Although the number of women who were interviewed was small, this may suggest that women who choose to have the office treatment are more motivated to tolerate and complete the procedure, which may also contribute to the reduced number of failed procedures in the office setting.

The strengths of this study include its size, the multicentre design, a population representative of the UK demographic, the relatively low rates of loss to follow-up and the tailoring of assessment of outcomes to the primary complaint. As this was a preference study, selection bias is an obvious limitation to the interpretation of the results. However, statistical adjustments were made for the obvious confounding factors including type of bleeding, surgical experience, removal method and the site, nature, size and number of uterine polyps.

In comparison to data from the parallel randomised controlled trial [14], the overall level of failed polypectomy in both groups was lower ( 9 versus $13 \%$; OR $=0.64,95 \% \mathrm{CI}=0.42$ to $0.99 ; p=0.05)$ and treatment success higher (82 versus $76 \%$; $\mathrm{OR}=1.4,95 \% \mathrm{CI}=1.0$ to $2.0 ; p=0.06)$. These findings are unlikely to be due to differences in demographics of the two studies as they were largely the same apart from a slightly older population in the preference study ( 2.4 years, $95 \% \mathrm{CI}=0.9$ to 3.7). It is more likely to reflect the selection of more favourable, better motivated women and technically 'less challenging' polyps to surgically remove in the office setting by the operating surgeon. However, the effect of counselling by individual surgeons on patient preference for treatment setting or indeed participation in the parallel randomised trial is unclear.

The 4:1 preference for office over inpatient polypectomy resulted in a smaller inpatient cohort and therefore the result estimates are less precise. Additional limitations of our preference study include varying practise between clinicians and a small number of participants failing to get their chosen treatment.

Office polyp treatment appears to be safe, feasible, acceptable and effective for the treatment of abnormal uterine bleeding in women expressing a preference for such treatment. Although this treatment is becoming more widespread, it is not universally available within national healthcare systems. This study demonstrates that when office treatment is available, most women recognise the potential benefits of office treatment and approximately $80 \%$ would choose it over inpatient treatment. In addition, this cohort study and the RCT have both shown that removing uterine polyps appears to alleviate abnormal uterine bleeding, for which data were previously lacking. Thus, there is evidence on both clinical and patient preference grounds, to support prioritising the provision of ambulatory gynaecology services such as office hysteroscopic polypectomy. An important caveat, however, is that women should be informed that office treatment may be associated with more pain and reduced acceptability compared with scheduled inpatient approaches to treatment under general anaesthesia, although they can be reassured that at least eight out of ten women find the procedure to be totally or generally acceptable. Although the preference study did not demonstrate an increased failure rate in the office group, this is likely to be due to confounding factors and the small inpatient 
group and as the RCT showed that failure was more likely, women should be informed of this, to allow them to make an informed decision about treatment setting. Future research should be directed at evaluating the influence of clinical characteristics and surgical technologies on the feasibility, acceptability and effectiveness of office hysteroscopic polypectomy.

This large, controlled observational study has shown that the majority of women expressing a treatment preference choose to have office treatment of uterine polyps associated with abnormal uterine bleeding. The findings of the study are subject to selection bias; however, they are consistent with the robust data derived from the parallel RCT. The findings, in particular the high levels of patient preference for office treatment, support the conclusions of the RCT that 'ambulatory' gynaecological therapeutic services should be made more widely available within healthcare systems. Currently, some women are being denied a choice of treatment setting and consequently are being subjected to the inconvenience and greater burden of inpatient hospital treatment, which if offered an alternative office treatment option, they could avoid.

Acknowledgments We thank the many women who participated in the OPT study. We also thank the following people: Richard Grey who provided initial statistical advice; and past and present members of OPT project management team: Laura Gennard, Liz Brettell, Lisa Leighton and Enid Darby (trial management); Tracy Bingham and Susan Sargent (research nurses); Mary Connor and Sian Jones (surgical advisors); Versha Cheed (statistics); Nicholas Hilken (database programmers).

OPT collaborative group We would like to acknowledge our National Health Service colleagues who supported recruitment for the trial: Barnsley District General Hospital, South Yorkshire: K Cannon, KA Farag, K Raychaudhuri, M Reid, A Zahid; Birmingham Heartlands/ Solihull Hospital, Birmingham: J Blunn, S Guruswami, S Irani, D Robinson; Birmingham Women's Hospital, Birmingham: T Bingham, TJ Clark, NAM Cooper, J Gupta, S Madari, D Mellers, S O'Connor, C O'Hara, M Pathak, V Preece, E Sangha, M Shehmar, P Trinham, A Wilson; Bishop Aukland General Hospital, County Durham: J Dent, J Macdonald, P Sengupta; Blackpool Victoria Hospital, Blackpool: C Brookes, J Davies; Bradford Royal Infirmary, Bradford: M Jackson, S Jones, H Ludkin, S Riddiough; Castle Hill Hospital, East Yorkshire: J Allen, T Cathcart, D Cox, S Ford, L Kenny, K Phillips, N Rawal, A Rodgers, J Siddiqui; Chelsea and Westminster Hospital, London: A Dine-Atkinson, S Kalkur, G Merriner, J Ben-Nagi, A Raza, R Richardson; University Hospital of North Staffordshire, Stoke-on Trent: I Hassan; City Hospital, Sunderland: D Edmundson, J Chamberlain, A Barge, P Wake, D Milford, E Walton; Countess of Chester Hospital, Chester: S Arnold, M Blake, MJ McCormack, N Naddad, J Hane, S Wood; Kidderminster Hospital, Worcester: M Labib, T Martin, S Moss, M Pathak; Liverpool Women's Hospital, Liverpool: N Aziz, L Harris, D Pattison; Manor Hospital, Walsall: J Pepper; Musgrove Park Hospital, Taunton: M Escott, G Fender; New Cross Hospital, Wolverhampton: M Saeed; Newham University Hospital, Plaistow: A Antoniou, R Chenoy; Norfolk and Norwich University Hospital, Norwich: E Morris, M Sule; Ormskirk and District General Hospital, Southport: A Cope, S Sharma, T Taylor; Queen Charlotte's and Chelsea Hospital, London: N Panay, C Rothan; Queen's Hospital, Romford: A Coker; Royal Blackburn Hospital, Blackburn: M Abdel-Aty, K Bhatia, S Gardiner, W Myint, M Willett; Royal Hallamshire Hospital, Sheffield: V Brown, C Bonner, M Connor, S Stillwell; Royal Infirmary of Edinburgh, Edinburgh: A Horne, S Milne, J
Rowan; Sandwell General Hospital, West Midlands: A Ewies, J Kabukoba; Shotley Bridge Hospital, County Durham: J Dent, P Sengupta; St Mary's Hospital, Manchester: R Biancardi, K Donnelly, L Dwyer, K Naidoo, I Pinton; Stafford Hospital, Stafford: K Chin, T Harrison, J Roger, D Sirdefield, J Stacey; Royal Oldham Hospital, Oldham: Z Anjum, N Aziz; The Royal Victoria Infirmary, Newcastle Upon Tyne: J Bainbridge, G Cosgrove, A Desai, J Gebbie, D Koleskas, P Ranka, M Roberts; Whiston Hospital, Merseyside: C Cunningham, C Nwosu, N Aziz.

Author's contributions TJC, LM, ED, SJ and JD were involved in designing the study as co-applicants. TJC oversaw the running of the trial and all of the authors contributed to the ongoing management of the trial. NAMC, TJC and the OPT collaborative group recruited patients to the trial. NAMC, TJC, PS, ED, LS and the OPT collaborative group collected data for the trial. LM performed the statistical analysis. ED and LS evaluated the qualitative data. The manuscript was drafted by NAMC and TJC with contributions from LM (statistics) ED (qualitative study). All the authors contributed to the interpretation of the results of the study and revised and reviewed the paper. The Birmingham Clinical Trials Unit did the randomisation and data management and monitoring.

\section{Compliance with ethical standards}

Conflict of interest All authors have completed the Unified Competing Interest form at www.icmje.org/coi disclosure.pdf. Prof Clark reports separate research grants from Hologic (formerly Cytyc) and Smith \& Nephew to conduct clinical trials in ambulatory care; and honoraria for training and lecturing and travel expenses from the following instrument manufacturers who produce health technologies that can be used in ambulatory care; Ethicon Women's Health; Hologic; Smith \& Nephew; Conceptus; Bayer. Dr. Smith reports a grant from Smith \& Nephew, during the conduct of the study, for a trial comparing techniques for office polypectomy. All other authors report no conflicts of interest.

Consent All persons gave their informed consent prior to their inclusion in the study.

Funding The study sponsors were the University of Birmingham and Birmingham Women's NHS Foundation Trust, and the study was funded by the National Institute of Health Research (NIHR) Health Technology Assessment Programme (06/404/84). The views and opinions expressed in this article are those of the authors and do not necessarily reflect those of the NIHR Health Technology Assessment Programme, the NIHR, the National Health Service or the English Department of Health.

Role of the funding source Neither the funder nor sponsor had any role in study design, data collection, interpretation or analysis or in writing the report for publication. The authors had full access to all the data from the study. The authors vouch for the accuracy and completeness of the data and analyses.

Data The corresponding author affirms that the manuscript is an honest, accurate and transparent account of the study being reported that no important aspects of the study have been omitted and that any discrepancies from the study as planned (and, if relevant, registered) have been explained.

The full dataset is available from the corresponding author. Consent was not obtained but the presented data are anonymised and risk of identification is low.

Ethical approval Ethical approval was obtained from the South West Research Ethics Committee on 15th February 2008. Reference number: 08/H0206/6. 
Open Access This article is distributed under the terms of the Creative Commons Attribution 4.0 International License (http:// creativecommons.org/licenses/by/4.0/), which permits unrestricted use, distribution, and reproduction in any medium, provided you give appropriate credit to the original author(s) and the source, provide a link to the Creative Commons license, and indicate if changes were made.

\section{References}

1. Spencer CP, Whitehead MI (1999) Endometrial assessment re-visited. Br J Obstet Gynaecol 106(7):623-632

2. Bradlow J, Coulter A, Brooks P (1992) Patterns of referral. Oxford Health Services Research Unit, Oxford

3. Nagele F, O’Connor H, Davies A, Badawy A, Mohamed H, Magos A (1996) 2500 outpatient diagnostic hysteroscopies. Obstet Gynecol 88(1):87-92

4. Clevenger-Hoeft M, Syrop CH, Stovall DW, Van Voorhis BJ (1999) Sonohysterography in premenopausal women with and without abnormal bleeding. Obstet Gynecol 94(4):516-520

5. van H, CD d, CE J, JB T, FW J (2007) Diagnostic hysteroscopy in abnormal uterine bleeding: a systematic review and meta-analysis. BJOG: Int J Obstet Gynaecol 114(6):664-675

6. Lasmar RB, Dias R, Barrozo PR, Oliveira MA, Coutinho ES, da Rosa DB (2008) Prevalence of hysteroscopic findings and histologic diagnoses in patients with abnormal uterine bleeding. Fertil Steril 89(6):1803-1807

7. Coloma CF, Paya AV, Diago Almela VJ, Costa CS, Valero FV, Lopez-Olmos J (1998) 2,000 out-patient diagnostic hyteroscopies: 8 years of experience [Spanish] dos mil histeroscopias diagnosticas ambulatorias: Experiencia de echo anos. Progresos en Obstetricia y Ginecologia 41(6):347-352
8. Lieng M, Istre O, Qvigstad E (2010) Treatment of endometrial polyps: a systematic review. Acta Obstet Gynecol Scand 89(8): 992-1002

9. Nathani F, Clark TJ (2006) Uterine polypectomy in the management of abnormal uterine bleeding: a systematic review. J Minim Invasive Gynecol 13(4):260-268

10. Marwah V, Bhandari SK (2003) Diagnostic and interventional microhysteroscopy with use of the coaxial bipolar electrode system. Fertil Steril 79(2):413-417

11. Cicinelli E, Tinelli R, Loiudice L, Loiudice I, Francavilla M, Pinto V (2010) Office polypectomy without anesthesia with Alphascope: a randomized controlled study. J Minim Invasive Gynecol 17(6 SUPPL. 1):796-799

12. Clark TJ, Godwin J, Khan KS, Gupta JK (2002) Ambulatory endoscopic treatment of symptomatic benign endometrial polyps. A feasibility study. Gynaecol Endosc 11(2-3):91-97

13. Clark TJ, Gupta JK (2005) Handbook of outpatient hysteroscopy. A complete guide to diagnosis and therapy. First ed. Hodder Education, London

14. Cooper NAM, Clark TJ, Middleton LJ, Diwakar L, Smith P, Denny E, et al. (2015) A randomised trial of outpatient versus inpatient uterine polyp treatment for abnormal uterine bleeding. Br Med J 350:h1398

15. EuroQol Group. EuorQol EQ-5D. http://www.euroqol.org/. 2013. 3-12-2013.

16. Shaw RW, Brickley MR, Evans L, Edwards MJ (1998) Perceptions of women on the impact of menorrhagia on their health using multiattribute utility assessment. Br J Obstet Gynaecol 105(11):1155-1159

17. Blizzard L, Hosmer DW (2006) Parameter estimation and goodness-of-fit in log-binomial regression. Biom J 48(1):5-22

18. Sterne JA, White IR, Carlin JB, Spratt M, Royston P, Kenward MG, et al. (2009) Multiple imputation for missing data in epidemiological and clinical research: potential and pitfalls. Br Med J 29(338):b2393

19. Rubin DB. Multiple Imputation for Nonresponse in Surveys. http:// onlinelibrary.wiley.com/doi/10.1002/9780470316696.fmatter/pdf. 1987. John Wiley and Sons. 